\title{
ANALISIS KEPUASAN PELANGGAN MENGGUNAKAN METODE ROUGH SET
}

\author{
Muhammad Ardiansyah Sembiring ${ }^{1}$, Raja Tama Andri Agus ${ }^{2}$ \\ Mustika Fitri Larasati Sibuea ${ }^{3}$ \\ STMIK Royal, Kisaran \\ e-mail: adinmantap88@gmail.com, ${ }^{1}$ rajatama2588@gmail.com, \\ bukmus.inaction@gmail.com
}

\begin{abstract}
Data mining is a process of Knowledge Discovery from Databases (KDD). $K D D$ is an activity that includes the collection, use of historical data to find regularities, patterns or relationships in large data sets. The Rough Set method is related to discreet data, rough sets are usually used in conjunction with other techniques to perform discreetization on datasets. The main purpose of rough set analysis is to synthesize a conceptual approach from the data obtained. This study aims to determine the level of customer satisfaction
\end{abstract}

Keywords: customer satisfaction, Rough Set, Data mining

\begin{abstract}
Abstrak: Data mining adalah proses dari Knowledge Discovery from Databases (KDD). KDD adalah kegiatan yang meliputi pengumpulan, pemakaian data, historis untuk menemukan keteraturan, pola atau hubungan dalam set data besar. Metode Rough Set berhubungan dengan discreet data, rough set biasanya digunakan bersamaan dengan teknik lain untuk melakukan discreetization pada dataset. Tujuan utama dari analisis rough set adalah untuk mensintesis pendekatan konsep dari data yang diperoleh. Penelitian ini bertujuan untuk mengetahui tingkat kepuasan pelanggan
\end{abstract}

Kata kunci: kepuasan pelanggan, Rough Set, Data mining

\section{PENDAHULUAN}

\begin{tabular}{|c|c|}
\hline Dalam & rangka \\
\hline $\begin{array}{l}\text { epuasan } \\
\text { nengalami }\end{array}$ & $\begin{array}{l}\text { pelanggan, } \\
\text { kesulitan }\end{array}$ \\
\hline
\end{tabular}
mempertahankan produksi instalasi air bersih sehingga kuantitas air bersih ke konsumen terganggu. Ketidak stabilan pasokan air baku ke instalasi produksi karena besaran debit air mengalami ketidak pastian dalam proses waktu dari satu musim ke musim kemarau lainnya, Undang-undang Dasar 1945 pasal 33 ayat 3 menyatakan bahwa bumi, air dan kekayaan alam yang terkandung didalamnya dikuasai oleh negara dan dipergunakan sebesar-besarnya untuk kemakmuran rakyat. Sumber daya air di Indonesia dikelola oleh Perusahaan Air Minum (PAM) yang mendapat wewenang dari pemerintah dalam pengelolaan kebutuhan konsumsi air bersih bagi masyarakat. Perusahaan Air Minum (PAM) yang berada di wilayah pemerintahan daerah dinamakan Perusahaan Daerah Air Minum (PDAM).

\section{METODE}

Metode Penelitian adalah cara ilmiah untuk mendapatkan data dengan tujuan dan kegunaan tertentu, cara ilmiah ber Rasional artinya bahwa penelitian dilakukan dengan cara-cara yang masuk di akal, sehingga kegiatan penelitian itu didasarkan pada ciri-ciri keilmuan, yaitu rasional, empiris dan sistematis. Rasional artinya bahawa penelitian dilakukan dengan cara-cara yang di akal, sehingga terjangkau oleh penalaran manusia. Empiris artinya bahwa cara-cara yang yang dilakukan itu dapat diamati oleh 
Available online at http://jurnal.goretanpena.com/index.php/JSSR

indra manusia sehingga orang lain dapat mengamati dan mengetahui cara-cara yang digunakan. Sistematis artinya proses yang digunakan dalam penelitian itu menggunakan langkah-langkah tertentu yang bersifat logika.

Dalam penelitian ini peneliti menggunakan metode deskriptif. Metode deskriptif adalah metode riset yang bertujuan untuk menjelaskan suatu peristiwa yang sedang berlangsung pada masa sekarang dan juga pada masa lampau. Dalam penelitian ini peneliti tidak memanipulasi data yang sedang diteliti. Metode riset ini dapat dibagi menjadi dua, yaitu Longitudinal (sepanjang waktu) dan Cross Sectional (waktu tertentu). Dalam penelitian ini peneliti menggunakan pendekatan kuantitatif yaitu penelitian yang dilakukan secara sistematis, terstruktur, serta terperinci. Pada pelaksanaaannya, metode

riset ini fokus pada penggunaan angka, tabel, grafik, dan diagram untuk menampilkan hasil data / informasi yang diperoleh pada sistem informasi yang digunakan.

\section{HASIL DAN PEMBAHASAN}

Studi kasus yang dilakukan pada kepuasan pelanggan. data pelangganakan dijadikan sampel untuk menganalisis data kepuasan pelanggan merupakan kriteria yang digunakan untuk menentukan tingkat kepuasan pelanggan.

Tabel. Kriteria Penilaian

\begin{tabular}{|c|c|c|c|c|c|}
\hline $\begin{array}{l}\text { Input / } \\
\text { Output }\end{array}$ & Kriteria & Variabel & Himpunan & Semesta & Range \\
\hline \multirow{9}{*}{ Input } & \multirow{3}{*}{$\begin{array}{l}\text { Tangible (Bukti } \\
\text { Langsung) }\end{array}$} & \multirow{3}{*}{$\mathrm{TA}$} & Baik & \multirow{3}{*}{$1-20$} & $15-20$ \\
\hline & & & Cukup & & $7-14$ \\
\hline & & & Kurang & & $1-6$ \\
\hline & \multirow{2}{*}{$\begin{array}{l}\text { Responsiveness } \\
\text { (Daya Tanggap) }\end{array}$} & \multirow{2}{*}{ RS } & Tinggi & \multirow{2}{*}{$1-8$} & $6-8$ \\
\hline & & & Rendah & & $1-5$ \\
\hline & \multirow{2}{*}{$\begin{array}{c}\text { Reliability } \\
\text { (Keandalan) }\end{array}$} & \multirow{2}{*}{$R L$} & Tinggi & \multirow{2}{*}{$1-8$} & $6-8$ \\
\hline & & & Rendah & & $1-5$ \\
\hline & \multirow{2}{*}{$\begin{array}{l}\text { Assirance } \\
\text { (Jaminan) }\end{array}$} & \multirow{2}{*}{ AS } & Tinggi & \multirow{2}{*}{$1-8$} & $6-8$ \\
\hline & & & Rendah & & $1-5$ \\
\hline \multirow{3}{*}{ Output } & \multirow{3}{*}{$\begin{array}{l}\text { Customer } \\
\text { Satisfaction } \\
\text { (Kepuasan } \\
\text { Pelanggan) }\end{array}$} & \multirow{3}{*}{ CS } & Sangat Puas & \multirow{3}{*}{$1-44$} & $34-44$ \\
\hline & & & Cukup Puas & & $16-33$ \\
\hline & & & Kurang Puas & & $1-15$ \\
\hline
\end{tabular}

Langkah pertama dengan menentukan informations systems. dijelaskan rekapitulasi hasil pengisian kuisioner dari pelanggan yang telah ditransformasi. Adapun data yang digunakan sebagai sampel dilakukan secara acak adalah 10 pelanggan.

\section{Tabel. Information Systems}

\begin{tabular}{|c|c|c|c|c|c|}
\hline \multirow{2}{*}{$\begin{array}{c}\text { Nama } \\
\text { Altematif }\end{array}$} & $\begin{array}{c}\text { Tangible } \\
\text { (Bukti } \\
\text { Langsung) }\end{array}$ & $\begin{array}{c}\text { Responsiveness } \\
\text { (Daya } \\
\text { Tanggap) }\end{array}$ & $\begin{array}{c}\text { Reliability } \\
\text { (Keandalan) }\end{array}$ & $\begin{array}{c}\text { Assurance } \\
\text { (Jaminan) }\end{array}$ & $\begin{array}{c}\text { Ouput } \\
\text { Satisfaction } \\
\text { (Kepuasan } \\
\text { Pelanggan) }\end{array}$ \\
\hline A001 & 15 & 6 & 6 & 6 & 34 \\
\hline A002 & 14 & 6 & 6 & 5 & 31 \\
\hline A003 & 20 & 8 & 8 & 8 & 44 \\
\hline A004 & 15 & 6 & 6 & 6 & 34 \\
\hline A005 & 11 & 4 & 6 & 4 & 24 \\
\hline A006 & 10 & 5 & 6 & 4 & 24 \\
\hline A007 & 15 & 7 & 6 & 6 & 34 \\
\hline A008 & 13 & 6 & 7 & 6 & 33 \\
\hline A009 & 16 & 6 & 6 & 7 & 35 \\
\hline A010 & 16 & 6 & 6 & 6 & 34 \\
\hline Sumber: Kuesioner Dengan PDAM \\
\multicolumn{5}{|l|}{ Langkah kedua } \\
\hline
\end{tabular}

menentukan informations systems dengan melakukan proses Decision System. Adapun Decision System dari kepuasan pelanggan ini adalah terdiri dari:

1. Atribut Kondisi, yaitu Tangible, Responsiveness, Reliability dan Assurance,

2. Atribut Keputusan, yaitu Customer Satisfaction.

Adapun Decision System yang ada dapat dengan contoh data yang akan digunakan adalah sebanyak 10 data.

\section{Tabel. Decision System}

\begin{tabular}{|c|c|c|c|c|c|}
\hline \multirow{2}{*}{$\begin{array}{c}\text { Nama } \\
\text { Alltematif }\end{array}$} & $\begin{array}{c}\text { Tangible } \\
\text { (Bukti } \\
\text { Langsung) }\end{array}$ & $\begin{array}{c}\text { Responsiveness } \\
\text { (Daya } \\
\text { Tanggap) }\end{array}$ & $\begin{array}{c}\text { Reliability } \\
\text { (Keandalan) }\end{array}$ & $\begin{array}{c}\text { Assurance } \\
\text { (Jaminan) }\end{array}$ & $\begin{array}{c}\text { Cuptomer } \\
\text { Satisfaction } \\
\text { (Kepuasan } \\
\text { Pelanggan) }\end{array}$ \\
\hline A001 & Baik & Tinggi & Tinggi & Tinggi & $\begin{array}{c}\text { Sangat } \\
\text { Puas }\end{array}$ \\
\hline A002 & Cukup & Tinggi & Tinggi & Rendah & Cukup Puas \\
\hline A003 & Baik & Tinggi & Tinggi & Tinggi & $\begin{array}{c}\text { Sangat } \\
\text { Puas }\end{array}$ \\
\hline A004 & Baik & Tinggi & Tinggi & Tinggi & $\begin{array}{c}\text { Sangat } \\
\text { Puas }\end{array}$ \\
\hline A005 & Cukup & Rendah & Rendah & Rendah & Cukup Puas \\
\hline A006 & Cukup & Rendah & Rendah & Rendah & Cukup Puas \\
\hline A007 & Baik & Tinggi & Tinggi & Tinggi & $\begin{array}{c}\text { Sangat } \\
\text { Puas }\end{array}$ \\
\hline A008 & Cukup & Tinggi & Tinggi & Tinggi & Cukup Puas \\
\hline A009 & Baik & Tinggi & Tinggi & Tinggi & $\begin{array}{c}\text { Sangat } \\
\text { Puas }\end{array}$ \\
\hline A010 & Baik & Tinggi & Tinggi & Tinggi & $\begin{array}{c}\text { Sangat } \\
\text { Puas }\end{array}$ \\
\hline Sumber: Kuesioner Dengan PDAM & & & \\
\hline
\end{tabular}


Available online at http://jurnal.goretanpena.com/index.php/JSSR

\begin{tabular}{|c|c|c|c|c|c|}
\hline \multicolumn{6}{|c|}{$\begin{array}{l}\text { pembentukan Equivalence Class. } \\
\text { Equivalence Class merupakan proses } \\
\text { pengelompokan objek-objek yang sama. } \\
\text { Pada Tabel } 4.5 \text { dapat dilihat hasil } \\
\text { pembentukan Equivalen Class, dimana } \\
\text { untuk dapat memperoleh Equivalen Class } \\
(\text { EC1 - EC4). }\end{array}$} \\
\hline \multicolumn{6}{|c|}{ Tabel. Equivalen Class } \\
\hline Objek & A & B & C & D & E \\
\hline $\mathrm{ECl}$ & Baik & Tinggl & Tinggl & Tinggi & Sangat Puas \\
\hline$E C 2$ & Cukup & \begin{tabular}{|l|} 
Tinggl \\
\end{tabular} & Tinggl & Rendah & Cukup Puas \\
\hline$E C 3$ & Cukup & Rendah & Rendah & Rendah & Cukup Puas \\
\hline$E C 4$ & Cukup & Tinggl & Tinggl & Tinggl & Cukup Puas \\
\hline
\end{tabular}

Langkah keempat dengan menentukan nilai discernibility matrixnya. Untuk mrndapatkan nilai discernibility matrix yaitu dengan mengklasifikasikan atribut yang berbeda antara objek ke-i dan objek ke-j (yang dilihat hanya atribut kondisi saja). Berdasarkan data diatas maka berikut ini adalah discernibilty matrix-nya:

Tabel. Dicernibilty Matrix

\begin{tabular}{|c|c|c|c|c|}
\hline Objek & EC1 & EC2 & EC3 & EC4 \\
\hline EC1 & $\mathrm{X}$ & $\mathrm{AD}$ & $\mathrm{ABCD}$ & $\mathrm{A}$ \\
\hline $\mathrm{EC} 2$ & $\mathrm{AD}$ & $\mathrm{X}$ & $\mathrm{BC}$ & $\mathrm{D}$ \\
\hline $\mathrm{EC} 3$ & $\mathrm{ABCD}$ & $\mathrm{BC}$ & $\mathrm{X}$ & $\mathrm{BCD}$ \\
\hline $\mathrm{EC} 4$ & $\mathrm{~A}$ & $\mathrm{D}$ & $\mathrm{BCD}$ & $\mathrm{X}$ \\
\hline
\end{tabular}

Langkah kelima dengan pembentukan Discernibility Matrix Modulo D. Discernibility Matrix Modulo $D$ adalah suatu matriks yang berisikan perbandingan antara data yang berbeda atribut kondisi dan atribut keputusan. Data dengan kondisi atribut yang berbeda, tetapi atribut keputusannya sama tetap dianggap sama. Untuk mendapatkan nilai discernibility matrix-nya yaitu dengan mengklasifikasikan atribut yang berbeda antara objek $k e-i$ (baris) dan objek $k e-j$ (kolom), jika sama maka diberikan tanda $\mathrm{X}$. Adapun Discernibility Matrix Modulo .

Tabel.Discernibility Matrix Modulo D

\begin{tabular}{|c|c|c|c|c|}
\hline Objek & EC1 & EC2 & EC3 & EC4 \\
\hline EC1 & $\mathrm{X}$ & $\mathrm{AD}$ & $\mathrm{ABCD}$ & $\mathrm{A}$ \\
\hline $\mathrm{EC} 2$ & $\mathrm{AD}$ & $\mathrm{X}$ & $\mathrm{X}$ & $\mathrm{X}$ \\
\hline $\mathrm{EC} 3$ & $\mathrm{ABCD}$ & $\mathrm{X}$ & $\mathrm{X}$ & $\mathrm{X}$ \\
\hline $\mathrm{EC} 4$ & $\mathrm{~A}$ & $\mathrm{X}$ & $\mathrm{X}$ & $\mathrm{X}$ \\
\hline
\end{tabular}

Langkah keenam dalam proses Rough Set berikutnya adalah Reduction. Penulis menggunakan Discernibility Matrix sebagai acuan untuk melakukan proses Reduction. Untuk data yang jumlah variabel yang sangat besar, tidak mungkin mencari seluruh kombinasi variabel yang ada, oleh karena itu dibuat suatu teknik pencarian kombinasi atribut yang dikenal dengan Quick Reduct yaitu dengan cara:

1) Nilai Indiscernibility yang pertama dicari adalah Indiscernibility yang kombinasi atribut yang terkecil yaitu

2) Kemudian lakukan proses pencarian dependency attributes jika nilai dependency attributes yang didapat sama dengan 1 maka Indiscernibility untuk himpunan minimal variabel adalah variabel tersebut.

3) Jika pada proses pencarian kombinasi atribut tidak ditemukan dependency attributes sama dengan 1, maka lakukan pencarian kombinasi yang lebih besar, dimana kombinasi variabel yang dicari adalah kombinasi dari variabel yang nilai dependency attributes paling besar. Lakukan proses 3 sampai diperoleh nilai dependency attributes sama dengan 1 . 
Available online at http://jurnal.goretanpena.com/index.php/JSSR

Tabel. Reduction

\begin{tabular}{|c|c|c|c|}
\hline Class & CNF of Boolean Function & Prime Implicant & Reduct \\
\hline $\mathrm{ECl}$ & $A V D D^{*} \mathrm{ABBCCVD}{ }^{*} \mathrm{~A}$ & A & $\{\mathrm{A}\}$ \\
\hline $\mathrm{EC} 2$ & $A V D$ & $(A),(D)$ & $\{A, D\}$ \\
\hline$E C 3$ & $\mathrm{AuBr}(\mathrm{CV})$ & $(A, B, C, D)$ & $\{A, B, C, D\}$ \\
\hline$E C A$ & A & $A$ & $\{A\}$ \\
\hline
\end{tabular}

Langkah ketujuh setelah didapatkan hasil dari Reduction yaitu menentukan General Rules nya. Adapun General Rules yang dihasilkan terdiri dari kombinasi atribut sebagai berikut:

\section{Tabel. General Rules}

\begin{tabular}{|c|c|c|}
\hline D & Reduction & Mate \\
\hline 1 & $\{A\}$ & $\begin{array}{l}\text { Tika Bulkti Langsung="Baik" maka Kepuasan Pelanggan } \\
\text { ""Sangat Puas" }\end{array}$ \\
\hline 2 & $\{A\}$ & $\begin{array}{l}\text { Tika Bulki Langsung="Cukup" maka Kepuasan Pelanggan } \\
\text { "Cukup Puas" }\end{array}$ \\
\hline 3 & $\{A, D\}$ & $\begin{array}{l}\text { Tika Bukti Langssung = "Cukup", Jaminan="Rendan" maka } \\
\text { Keppuasan Pelanggan="Cukup Puas" }\end{array}$ \\
\hline 4 & $\{A, D\}$ & $\begin{array}{l}\text { Tika Bukti Langsung= "Baik", Jaminan="Tinggi" maka } \\
\text { Keppuasan Pelanggan="Cukup Puas" or" "Sangat Puas" }\end{array}$ \\
\hline 5 & $\{A, D\}$ & $\begin{array}{l}\text { Jika Butki Langsung = "Cukup", Jaminan="Rendah" maka } \\
\text { Keppuasan Pelanggan="Cukup Puas" }\end{array}$ \\
\hline 6 & $\{A, B, D, D\}$ & $\begin{array}{l}\text { Jika Butti Langsung = "Cuhup", Daya Tanggap="Rendah", } \\
\text { Keandalan ="Rendah", Jaminan="Rendal" maka Kepuasan } \\
\text { Pelanggan="Cukup Puas" }\end{array}$ \\
\hline & $\{A, B, C, D\}$ & $\begin{array}{l}\text { Tika Bukti Langsung= "Baik", Daya Tanggap= } \\
\text { "Tinggi" Keandalan ="Tinggi", Jaminan="Tinggi" maka } \\
\text { Kepuasann Pelangggan="Cukup Puas" of" "Sangat Puas" }\end{array}$ \\
\hline 8 & $\{A, B, D, D\}$ & $\begin{array}{l}\text { Jika Butti Langsung = "Cuhup"," Daya Tanggap=", Tinggi", } \\
\text { Keandalan ="Tinggi"," Jaminan="Rendal" maka Kepuasan } \\
\text { Pelanggan="Cukup Puas" }\end{array}$ \\
\hline
\end{tabular}

\section{SIMPULAN}

General rule/informasi yang di hasilkan oleh metode rough set dapat membantu pengelola usaha dalam mengetahui tingkat kepuasan pelanggan yang diharapkan dapat dijadikan dasar dalam mengambil kebijakan untuk kepuasan pelanggan.

\section{DAFTAR PUSTAKA}

Devara, M. R., \& Efendi, R. (2016). Perancangan Aplikasi MLearning Bahasa Inggris Berbasis Client Server. Rekursif: Jurnal Informatika, 4(3).

Nasution, A., \& Siddik, M. (2020, August). IMPACT OF USING MOBILE LEARNING APPLICATIONS IN THE LEARNING PROCESS. In International Conference on Social, Sciences and Information Technology (Vol. 1, No. 1, pp. 37-42).

Paruwansyah, G. A. (2018). Aplikasi Pemesanan Catering Berbasis Website Menggunakan Metode Rapid Application Development (RAD) Pada CV Maharani (Doctoral dissertation, POLITEKNIK NEGERI SRIWIJAYA).

Siddik, M., \& Nasution, A. (2018, September). Teknologi Push Notifikasi Berbasis Android Untuk Informasi Perkuliahan (Studi Kasus: STMIK Royal Kisaran). In Seminar Nasional Royal (SENAR) (Vol. 1, No. 1, pp. 41-44). 